\title{
Experimental Study on the Optimization of a Diversion Engineering in Lower Reaches of Fuhe River
}

\author{
Zhichao Wang ${ }^{1, *}$, Xinfa $\mathrm{Xu}^{1}$, Zhiwen Huang ${ }^{1}$ and Wensun $\mathrm{You}^{1}$ \\ ${ }^{1}$ Jiang Xi Provincial Institute of Water Sciences, 330029 Nanchang, China
}

\begin{abstract}
In jiangxi province, china, a new river will be excavated in the southern part of Qinglan Lake to drainage the main flow of Fuhe River into the Lake to improve the local flood prevention and navigation problems. A physic model is established to analyze the changes of flow characteristics under different engineering schemes. The research shows that water level decreases $1.91 \mathrm{~m}$, flow velocity of the upstream increases to $4.83 \mathrm{~m} / \mathrm{s}$, under $\mathrm{P}=5 \%$ River flood, which means the diversion engineering can significantly relieve the local flood pressure, but increase the scouring risks of wading buildings such as piers and embankments. Then the further optimization study shows that scheme 3 not only reduced the engineering quantity, but also decreased velocity increase rate from $61 \%$ to $48 \%$.
\end{abstract}

\section{INTRODUCTION}

River regulation engineering plays an important role in the development of human society[1;2]. Human beings adjust the flow characteristics and flow capacity of watercourses through engineering measures to meet the needs of water supply, energy, transportation and safety [3-7]. The river under manual intervention has many favorable conditions. For example, embankments stabilize the shoreline of the river, channel management ensures the stable trend of the river, and regular flow regulation solves people's demand for water.

Nowadays, more and more ecological environment concepts have been integrated into river regulation engineering, and the requirements for maintaining the ecological environment of watercourses are getting higher. For example, Nilsson[2], Christer[8] and others believed that the dam built has blocked the watercourse and restricted the biological migration, which greatly restricts the ability of many organisms to adapt to environmental changes through migration. Chaparro[9] et al. believed that river regulation would affect the functional diversity of flood plain wetlands, and lateral slope and water level fluctuation are the main factors driving plankton diversity in the region. Since the promulgation of the EU Water Framework Directive in 2000 [10], researchers in EU countries have taken a series of measures to help improve the water quality of rivers and restore habitat biodiversity. For example, in Germany, France, Austria and the Netherlands, a large number of riverbank ecologization work has been carried out [11-13].

However, on the other hand, without the limitation of human engineering, the watercourse evolution would be complicated and lasting for long, which are great challenges to the watercourse management. For example, after 10 years of riverbank erosion since the demolition of the protection engineering for the navigable reach of the Meuse River in Holland, a series of unpredictable inclined bays have emerged [13]. When losing the restriction of human engineering, the evolution of rivers is affected by natural conditions such as flow pattern, geology, vegetation, climate, etc., as well as human activities $[7 ; 13]$. Therefore, there are still many problems to be studied on how to maintain the balance between man-made constraints and natural ecology. And for a new river regulation engineering, the first thing to do is to grasp the impact of the project implementation on the flow characteristics as fully and truly as possible, so as to provide support for the subsequent demonstrations and improvements.

Fuhe River is located in the southeast of Jiangxi Province, China and is one of the five major rivers in the Poyang Lake Basin. There are many beaches and bends in the tail reach, resulting in a poor shipping condition. In addition, the reach has long embankments, some of which have yet to be repaired, which raising the flood risk. Therefore a water diversion engineering in Tacheng Township of Nanchang city is proposed, as shown in Figure 1. A new river will be excavated in the southern part of Qinglan Lake to drainage the main flow of Fuhe River into the Lake. The engineering is expected to shorten the embankment, reduce the obstacles of flood, and improve shipping conditions. However, the diversion engineering would also fundamentally change the flow characteristics in the region, which brings many uncertain impacts. This study analyzes the flow characteristics of the engineering reach through experiments, and provides support for the subsequent optimization designs.

\footnotetext{
* Corresponding author: pyhnszz@163.com
} 

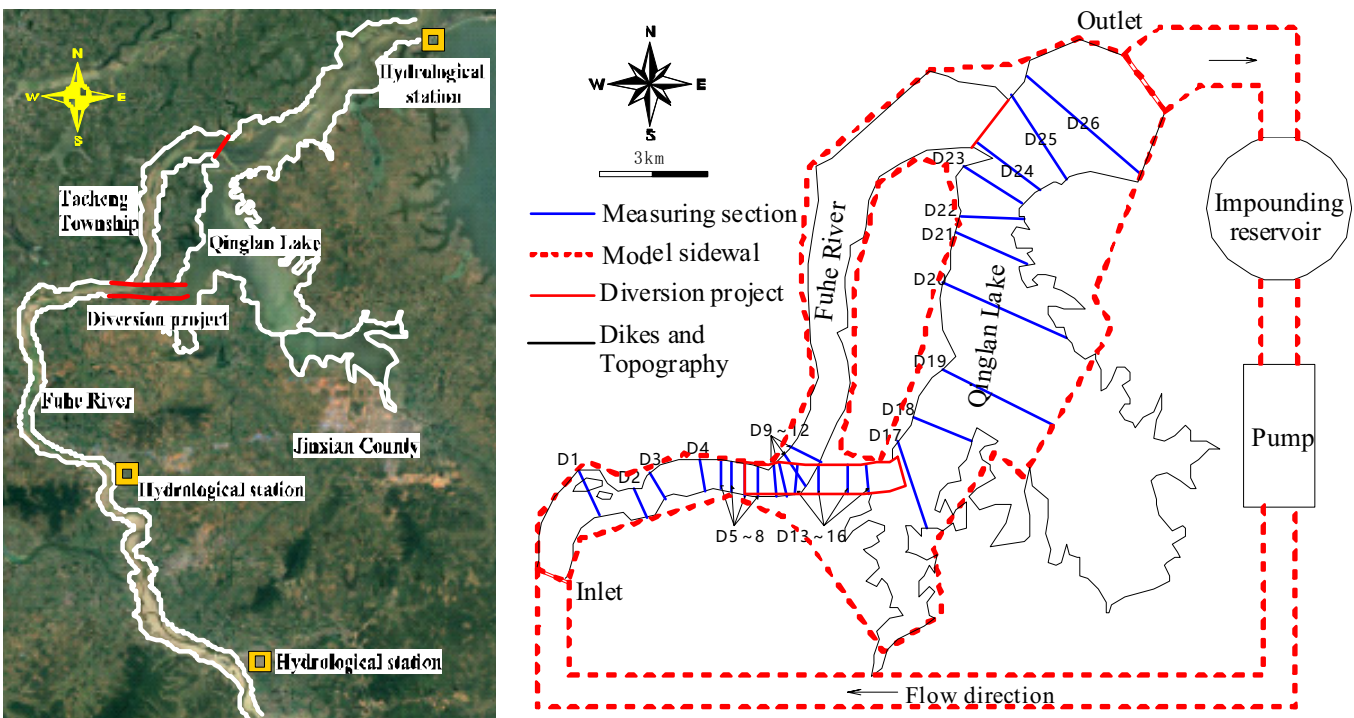

Figure 1. Model schematic diagram of the diversion engineering
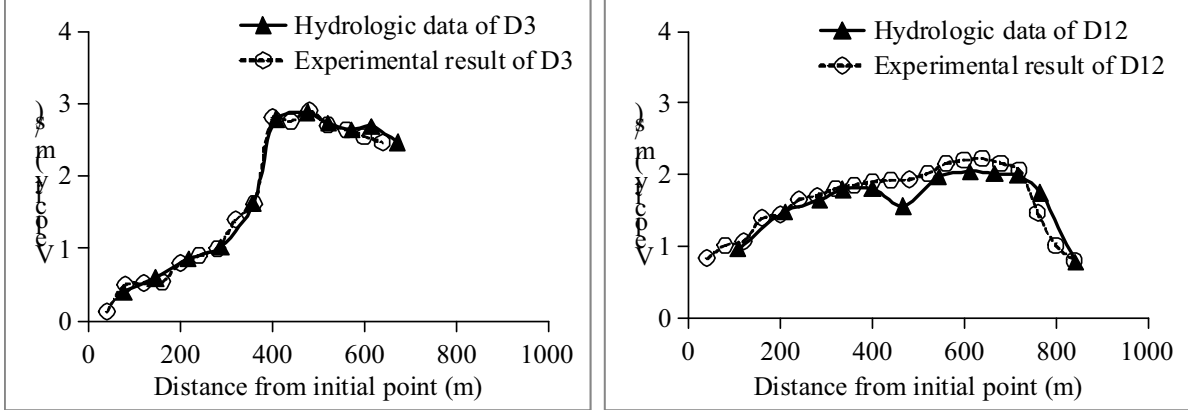

Figure 2. Verification of section velocity distribution $\left(\mathrm{Q}=5780 \mathrm{~m}^{3} / \mathrm{s}\right)$

\section{Model Design and Verification}

The research range and survey sections arrangement of the model test are shown in Figure 1. The inlet and outlet of the model are located $8.5 \mathrm{~km}$ upstream and $18.5 \mathrm{~km}$ downstream of the engineering. As the design scheme shows, the diversion engineering is $4.4 \mathrm{~km} \mathrm{long,}$ including $2 \mathrm{~km}$ excavation, and $1.8 \mathrm{~km}$ and $0.6 \mathrm{~km}$ dredging for upstream and downstream, and the original river is blocked. The new river with bottom width $750 \mathrm{~m}$, top width $822 \mathrm{~m}$, Longitudinal slope $0.15 \%$. There are two bridges within $2.5 \mathrm{~km}$ upstream of the engineering. 26 survey sections are arranged on the model, of which D1 $\sim$ D12 are located on the Fuhe River, D13 D16 are located in the engineering, and D17 D26 are arranged in the Qinglan Lake.

Table 1. The similarity conditions.

\begin{tabular}{|c|c|c|c|c|c|}
\hline $\begin{array}{c}\text { Similarity } \\
\text { conditions }\end{array}$ & $\begin{array}{c}\text { Horiz } \\
\text { ontal }\end{array}$ & $\begin{array}{c}\text { Verti } \\
\text { cal }\end{array}$ & $\begin{array}{c}\text { Veloc } \\
\text { ity }\end{array}$ & $\begin{array}{c}\text { Rough } \\
\text { ness }\end{array}$ & flux \\
\hline Scale & $1: 200$ & $1: 80$ & $1: 8.94$ & $1: 1.31$ & $1: 143108$ \\
\hline
\end{tabular}

Table 2. Water surface line verification $\left(\mathrm{Q}=5780 \mathrm{~m}^{3} / \mathrm{s}\right)$

\begin{tabular}{|c|c|c|c|c|c|}
\hline Survey section & D1 & D3 & D5 & D8 & D12 \\
\hline Hydrologic data $(\mathrm{m})$ & 21.94 & 21.49 & 20.99 & 20.42 & 19.74 \\
\hline
\end{tabular}

\begin{tabular}{|c|c|c|c|c|c|}
\hline Test result $(\mathrm{m})$ & 21.88 & 21.43 & 20.92 & 20.40 & 19.74 \\
\hline Deviation $(\mathrm{m})$ & -0.06 & -0.06 & -0.07 & -0.02 & 0.00 \\
\hline
\end{tabular}

Similarity conditions of the experiment are shown in Table 1. The verification shows that the experimental result matches good with the hydrologic data, which means the model meets the hydrodynamic similarity conditions, sees in Table 2 and Figure 2.

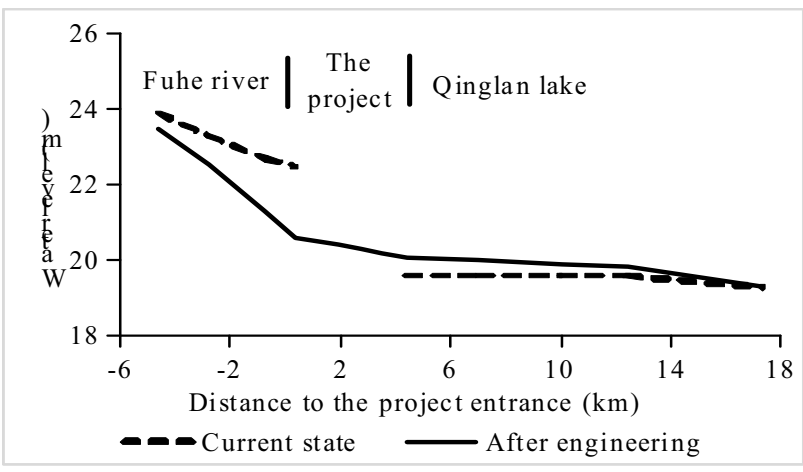

Figure 3. Verification of section velocity distribution $(\mathrm{P}=5 \%)$

\section{Test analysis of design scheme}

The diversion engineering shortened the flooding journey into Poyang lake and improved the flood 
discharge capacity. Water level on the upper reaches drop down, with $1.91 \mathrm{~m}$ decrease at the engineering entrance sees in Figure 3. However, due to the increase of water surface slope, the flow velocity of the river increases, especially at the engineering entrance increases from $3.0 \mathrm{~m} / \mathrm{s}$ to $4.83 \mathrm{~m} / \mathrm{s}$, which is not conducive to the safety of bridges and embankments. In addition, as the mainstream leans to the left bank, the engineering's discharge capacity is not fully utilized, as shown in Figure 4.

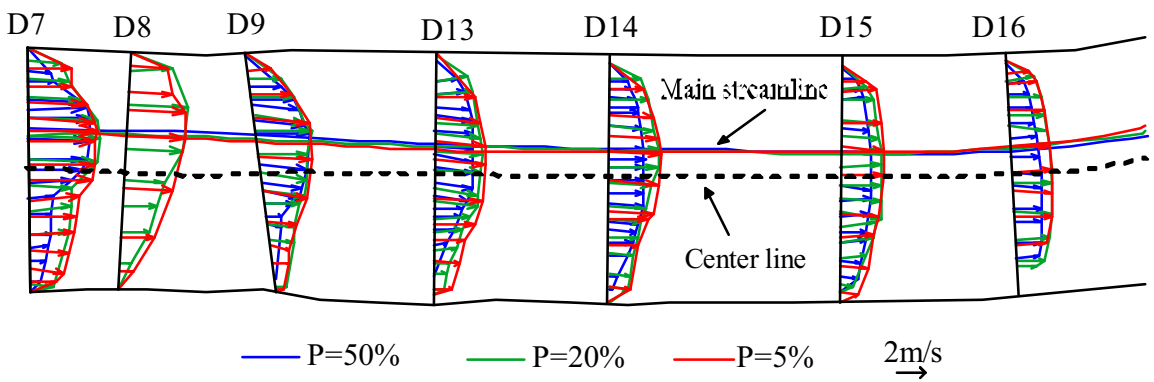

Figure 4. Velocity distribution in the diversion engineering

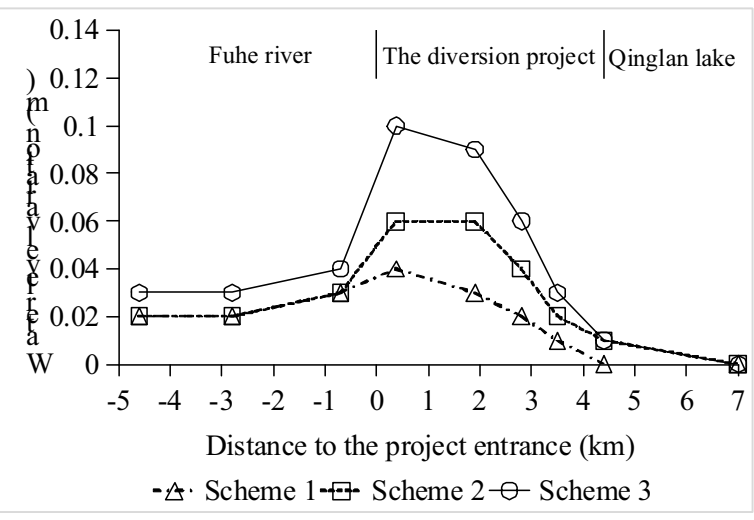

Figure 5. Water level change of the Optimization Schemes relative to the Design Scheme under river flood $\mathrm{P}=5 \%$

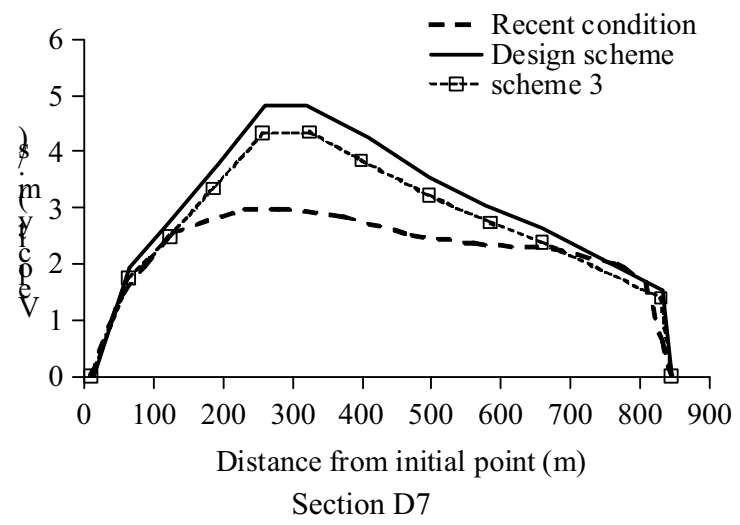

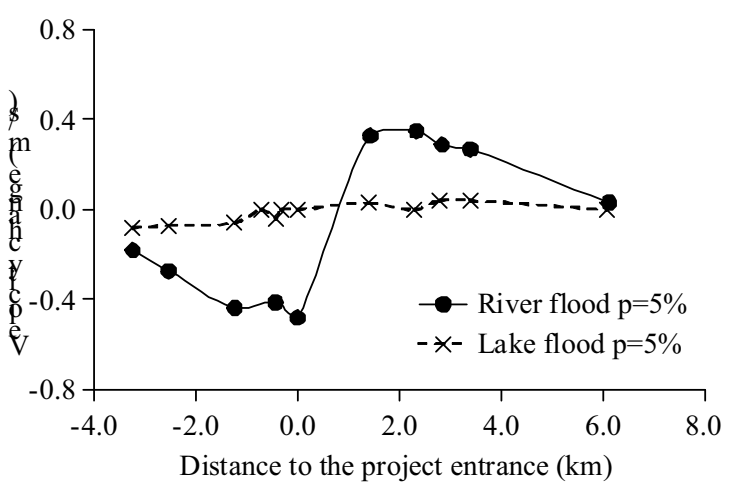

Figure 6. Velocity variation of Scheme 3 relative to the Design Scheme under river flood $\mathrm{P}=5 \%$

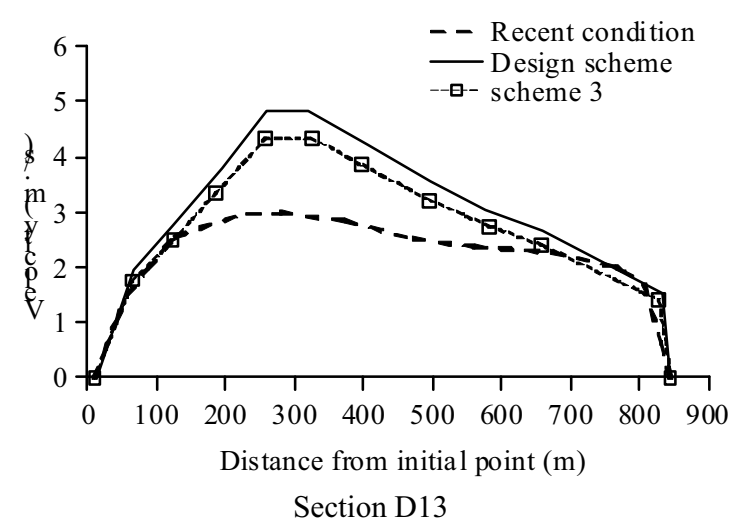

Figure 7. Velocity distribution of typical sections under river flood $\mathrm{P}=5 \%$

\section{Scheme optimization}

Therefore, to further improving the safety of wading buildings and reducing excavation, three Optimization Schemes are proposed, such as Scheme 1 river width narrowed by $50 \mathrm{~m}$ from right bank, Scheme 2 river longitudinal slope decreased to $0.10 \%$, Scheme 3 combine Scheme 1 and Scheme 2.

After the optimization, the water rise up less than $0.1 \mathrm{~m}$, which has little impact compared to the drop of $1.91 \mathrm{~m}$, as shown in Figure 5. Among them, Scheme 3 has the minimum excavation amount on the premise that it has little influence on the discharge capacity. The flow velocity at the entrance and upstream of the project generally decreases, and the downstream velocity increases, as shown in Figure 6. The areas with large velocity variation are located at the entrance (D7) and $2 \mathrm{~km}$ downstream (D13), as shown in Figure 7 . According to the design scheme the maximum velocity increases from $3.0 \mathrm{~m} / \mathrm{s}$ (recent condition) to $4.83 \mathrm{~m} / \mathrm{s}$ with an increase of $61 \%$. After the optimization, the maximum velocity drops to $4.35 \mathrm{~m} / \mathrm{s}$, increase rate drops to $48 \%$. 


\section{Conclusion}

The diversion engineering shortened the flooding journey into Poyang lake and improved the flood discharge capacity. Water level on the upper reaches drop down, with $1.91 \mathrm{~m}$ decrease at the engineering entrance. However, the engineering results in the increasing of flow velocity on upstream, and rises up the risk of scouring damage to the bridges and embankments. In addition, as the mainstream leans to the left bank, the engineering's discharge capacity is not fully utilized.

After the optimization, the water rise up less than $0.1 \mathrm{~m}$, which has little impact compared to the drop of $1.91 \mathrm{~m}$, the velocity increase rate drops from $61 \%$ to $48 \%$. Among them, Scheme 3 has the minimum excavation amount on the premise that it has little influence on the discharge capacity.

Narrowing the new river can concentrate the mainstream and reduce excavation, but higher requirements are put forward for the scour prevention of downstream. Slowing the bottom slope will not lead to adverse effects, so it is recommended to further optimize the longitudinal bottom slope.

\section{Acknowledgments}

This work was financially supported by the National Key R\&D Program (2018YFC0407605), the Key R\&D Program of Jiangxi Province (20203BBGL73224, 20203BBGL73221), Jiangxi Water Conservancy Science and Technology Project (201820YBKT11, 201821ZDKT06).

\section{References}

1. Petts G E. River regulation (Environmental Geology, Springer, Netherlands, 1999)

2. Nilsson C, Reidy C A, Dynesius $M$, et al. Fragmentation and Flow Regulation of the World's Large River Systems. Science, 308, 405-408 (2005)

3. Yoshikawa S, Cho J, Yamada H G, et al. An assessment of global net irrigation water requirements from various water supply sources to sustain irrigation: Rivers and reservoirs. Hydrology and Earth System Sciences, 18,4289-4310 (2014).

4. Ma Y J, Li X Y, Wilson M, et al. Water loss by evaporation from China's South-North Water Transfer Project. Ecological engineering, 95, 206215, (2016)

5. Liu M, Zhang H-W. Correction of the Artificial Influence on Dredging Volume in the Yangtze Estuary Deep-water Channel. IOP Conference Series: Earth and Environmental Science, 022004 (2019)

6. Zhang S, Jing Z, Li W, et al. Study of the flood control scheduling Scheme for the Three Gorges Reservoir in a catastrophic flood. Hydrological Processes, 32, 1625-1634 (2018)
7. Liu G W. On geo-basis of river regulation-A case study for the middle reaches of the Yangtze River. Science in China, Series E: Technological Sciences, 51, 494-505 (2008)

8. Christer N, Kajsa B. Alteration of Riparian Ecosystems Caused by River Regulation. BioScience, 50, 783-792 (2018)

9. Chaparro G, O'farrell I, Hein T. Multi-scale analysis of functional plankton diversity in floodplain wetlands: Effects of river regulation. Science of the Total Environment, 667, 338-347 (2019)

10. Kallis G, Butler D. The EU water framework directive: measures and implications. Water Policy, 3, 125-142 (2001)

11. [11]Schmitt K, Schäffer M, Koop J, et al. River bank stabilisation by bioengineering: potentials for ecological diversity. Journal of Applied Water Engineering and Research, 6, 262-273 (2018)

12. Liedermann $M$, Tritthart $M$, Gmeiner $P$, et al. Typification of vessel-induced waves and their interaction with different bank types, including management implications for river restoration projects. Hydrobiologia, 729, 17-31 (2014)

13. Duró G, Crosato A, Kleinhans M G, et al. Distinct patterns of bank erosion in a navigable regulated river[J]. Earth Surface Processes and Landforms, 45, 361-374 (2020) 